\title{
Proceeding
}

9th INSHS International Christmas Sport Scientific Conference, 4-6 December 2014. International Network of Sport and Health

Science. Szombathely, Hungary

\section{Analysis of erring in selected orienteering runners}

\author{
PAVLINA CHALOUPSKA \\ Department of Leisure and Tourism, Faculty of Informatics and Management, University of Hradec Kralove, Czech \\ Republic
}

\begin{abstract}
Chaloupska, P. (2015). Analysis of erring in selected orienteering runners. J. Hum. Sport Exerc., 9(Proc1), pp.S340-S344. The aim of this paper is to analyze causes of errors made by the selected elite orienteering runners, in qualitative research. Four elite orienteering runners in junior categories were monitored in September and October 2011, based on use of modern recording equipment: SPORT IDENT and GPS. The sample was analyzed in 10 races, which were held in the given period of 2 months. Based on the analysis of the data from the recording devices and based on interviews with the participants the most frequent types of errors were specified and their causes determined. The research study provides a significant contribution to the improvement of the training process in orienteering. Key words: ORIENTEERING, ERRING, TRAINING PROCESS.
\end{abstract}

Corresponding author. University of Hradec Kralove, Faculty of Informatics and Management, Department of Leisure and Tourism, Czech Republic. Rokitanskeho 62, 50003.

E-mail: pavlina.chaloupska@uhk.cz

9th INSHS International Christmas Sport Scientific Conference, 4-6 December 2014. International Network of Sport and Health Science. Szombathely, Hungary.

JOURNAL OF HUMAN SPORT \& EXERCISE ISSN 1988-5202

(C) Faculty of Education. University of Alicante

doi:10.14198/jhse.2015.10.Proc1.23 


\section{INTRODUCTION}

This paper is focused on the research of performance of orienteering runners. Orienteering is a sport in which the performance depends not only on a physical component, but it is also affected by a psychological component. Working with a map puts high demands on mental activity during the race. Orienteering involves a number of processes that are constituted by aspects of cognition: planning, thinking, remembering, recognition (Johansen 1997). The performance of orienteering runners may be influenced by the so-called errors, which may occur in the race for many reasons and thereby decline the result. The aim of this paper is to analyze causes of errors made by the selected elite orienteering runners. Following this analysis a list of most causes of errors was made. For each competitor separately statistics of each occurred error, and their proportion in the total time loss in the race was made. The findings of this research will be used to improve training process of orienteering runners. Most authors who are concerned with orienteering are from Scandinavia and Switzerland. The first studies related to erring, run tactics and mapping were published by Gjerset (1975), Ackerblom (1979), Hogedal and Putkonen (1975), Johansen (1979) and Nilson (1980). All the above mentioned studies were systematically reviewed by Seiler (1987) in Scientific Journal of Orienteeering. Latest publications are three monographs by Dresel (2008), Ferguson (2013) and McNeill (2014), where is a chapter dedicated to erring in orienteering. Currently on problem of erring in the Czech Republic publishes systematically head coach of the Czech national team Radovan Novotný in the journal Orientačni běh - časopis orientačních sportů.

\section{MATERIAL AND METHODS}

The research is qualitative, aimed at cognitive processes of orienteering runners related to erring. Individual performance is influenced by external and internal factors. The basic method is an analysis of data collected in the measurements and interviews. Verbal reports allow to identify relevant aspects of cognitive processes. The method of simulated recalls means drawing the route in orienteering map while being interviewed.

\section{Participants}

Four elite orienteering runners in junior categories were monitored and interviewed in September and October 2011. The selection was intentional, since the performance in junior category is more influenced by errors, and also the training process is focused on this problem.

\section{Measures}

The sample was analyzed in 10 races, which were held in the given period of 2 months. There were different types of courses (middle, long and sprint). The data were recorded using modern equipment: SPORT IDENT (electronic punching system, which allows detailed analysis of time splits throughout the race) and GPS (global position system, which allows to track the athletes during the race)

\section{Procedure}

For each race there was a detailed analysis of GPS and SPORT IDENT data, supplemented by a commentary of the athletes on their individual errors. GPS device and a detailed drawing of the route helped reveal any deviation from the ideal track. SPORT IDENT revealed a time loss of every split. The competitors were interviewed straight after each race to achieve an explanation of every identified time loss. An error was defined as a time loss identified by the participant bigger than 10 seconds. Due to the qualitative nature of the research, the participants did not have a list of causes of errors in advance and so 
they identified the individual causes on their own. This approach was chosen due to the aim of the research, which was to determine most of the causes of errors in orienteering

\section{RESULTS}

Based on data analysis the causes of errors were categorized in four main groups:

- Technical and tactical causes. This is the largest group of causes. Causes of errors are always related to mapping techniques and tactics before and during the race.

- Physical causes. Here are classified errors related to running technique, fatigue and running speed.

- Psychological causes. This group includes errors related to cognitive processes during the race.

- Uninfluencable causes. Some errors arise independently of the athletes themselves. They can be caused e.g. by changing weather conditions.

All the discovered causes of errors are in the table 1.

Table 1. Causes of errors

\begin{tabular}{|c|c|c|c|}
\hline Technical and tactical causes & Physical causes & Psychological causes & $\begin{array}{l}\text { Uninfluencable } \\
\text { causes }\end{array}$ \\
\hline $\begin{array}{l}\text { Lack of pre-race preparation } \\
\text { Unsuitable tactics at the beginning of } \\
\text { the race } \\
\text { Tactically wrong chosen route } \\
\text { Route not prepared in advance } \\
\text { Missing strategy } \\
\text { Unfluent mapping } \\
\text { Mapping at the wrong moment } \\
\text { Underestimating of a seemingly easy } \\
\text { route } \\
\text { Ignoring the errors } \\
\text { Incorrectly oriented map } \\
\text { Inattention at the last clue } \\
\text { Wrong direction determination } \\
\text { Running through rugged clearing } \\
\text { Struggling through thicket } \\
\text { Inconsistent map reading } \\
\text { Failure to read the description of the } \\
\text { check point } \\
\text { Ignoring clues and lines } \\
\text { A different idea what the terrain will } \\
\text { look like } \\
\text { Course setting trap - difficult passage, } \\
\text { crossing } \\
\text { Wrong run off the check point } \\
\text { Incorrectly distance estimation }\end{array}$ & $\begin{array}{l}\text { Too fast running } \\
\text { Fatigue } \\
\text { Too Slow Running } \\
\text { Poor running } \\
\text { technique }\end{array}$ & $\begin{array}{l}\text { Stress } \\
\text { Loss of concentration } \\
\text { Lack of confidence } \\
\text { Rashness } \\
\text { Indecisiveness } \\
\text { Over motivation } \\
\text { Omitting at the end of } \\
\text { the race }\end{array}$ & $\begin{array}{l}\text { Tricky place on the } \\
\text { map } \\
\text { Illegibility of the } \\
\text { map } \\
\text { Urban traffic } \\
\text { Weather }\end{array}$ \\
\hline
\end{tabular}


An example is the participant no. 4. He is a man, 18 years old, a competitor, who participated on the EYOC 2009 (European Youth Orienteering Championships). In the 10 races he made 38 errors with the total time loss of 20 minutes and 30 second. Concerning erring six out of his seven big errors were with an option to prevent a significant time loss. During his ten races the participant erred seven times at the end of the race when the finish line remained up to three controls. Eight times the participant made the so called doublefault, which means making an error in two consecutive splits. The figure 1 shows the percentage of the main causes on the total time loss by the participant no. 4 .

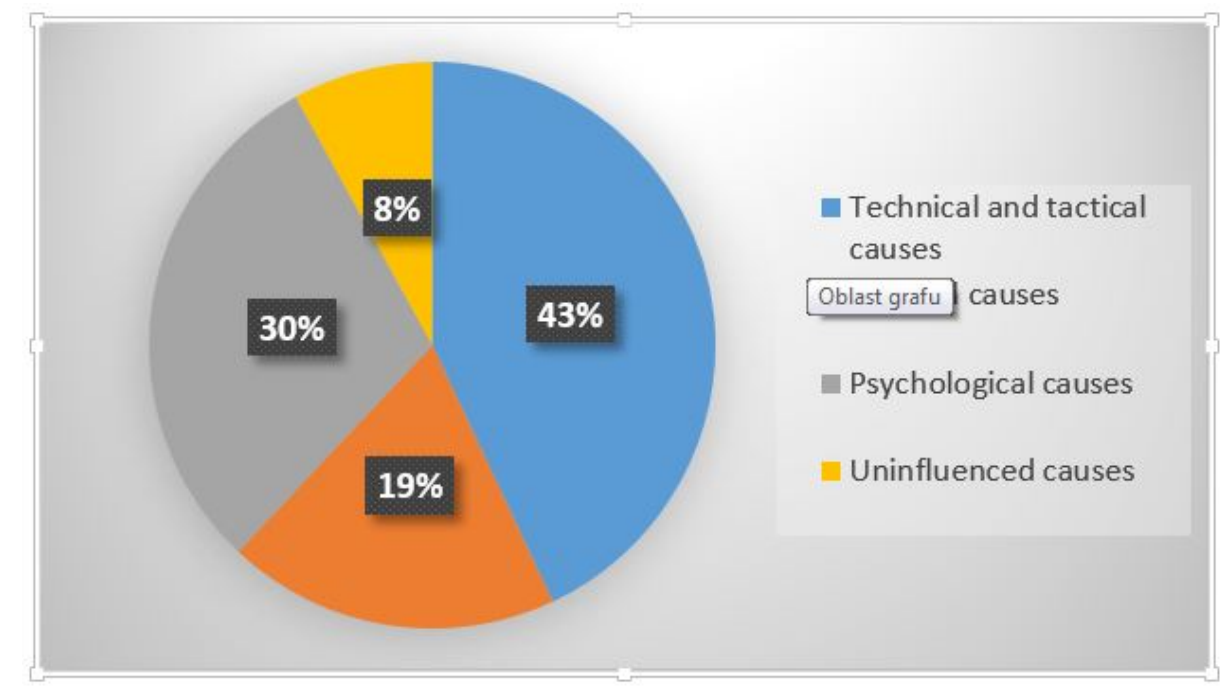

Figure 1. The percentage of the main causes on the total time loss, participant no. 4

Beyond the research an evaluation of all the competitors was worked out. The most frequent causes of mistakes of all analyzed data were too fast running, lack of confidence, tactically wrong chosen route or unprepared route in advance. Analysis and evaluation of the data from interviews suggested that, most of the errors, which caused a time loss of one minute or more, could have been avoided at the moment when the competitor realized that he or she would probably make mistake. Ignoring mistakes always led to even bigger time loss (71\%).The biggest percentage of errors of the competitors had technical-tactical causes (min.55\%), then psychological causes (27\%), physical causes (14\%) and the lowest percentage had uninfluencable causes $8 \%$. This results are in agreement with findings of the above mentioned studies.

\section{DISCUSSION}

Seiler (1987) claimed, that there exists wonderful confusion about the possible reasons for errors and it is obvious that an operationalization would raise enormous problems. It was based on previous research studies, which were not consistent and wasn't based on standardized methods. Gjerset (1975) classified only 4 reasons for the errors, Acerblom (1979) defined also only 4 causes without concentrating on elite orienteers. Hogedal (1975) suggested, that the main cause of erring is difficulty to choose an adequate running speed. Nilson (1980) defined eight possible reasons for orienteering errors.

The research described in this paper has significantly extended the number of defined causes of errors. This list will help to monitor each individual and modify their training schedule according to the needs. The research is fully consistent with the statement, that a systematical analysis over several years is considered to be necessary to develop the athlete ability to recognize time loss and to attribute exactly the causes of the loss (Dresel, 2008). 
Crampton (1988) and McNeill (2014) reached completely different results. Crampton (1988) found out, that getting lost occurs primarily through parallel error. McNeill (2014) states, that of time los, $95 \%$ occurs when approaching checkpoints. The results of this paper do not correspond with these statements. The application of this research results will help to monitor a larger number of competitors for several years and standardize the list of causes of errors.

\section{CONCLUSIONS}

Erring in orienteering is such a complex issue that it is not easy to determine only one cause of the error. One cause usually induces next cause or mistake arises as an influence of simultaneously more causes. Erring is also a very individual issue related to the nature of the competitor. Each personality has different character traits, different thinking patterns and different ability of concentration. Importance of this research is primarily identifying individual mistakes and creation of their list. Currently is created a simple application in which could competitors record their mistakes and led their individual statistics. This application will be great training and coaching tool for elite orienteers as it will be possible to focus on eliminating the causes of individual mistake.

\section{REFERENCES}

1. Akerblom, H. (1979). Orienteringsteknisk undersökning frän FM. Helsinki: Finlands Svenska Orienteringsförbund.

2. Crampton, J.W. (1988). The Cognitive Processes of Being Lost. Scientific Journal Of Orienteering., 4, pp. 34-46.

3. Dresel, U., Fach, H., \& Seiler R. (2008). Orientierungslauf-Training. Aachen: Meyer \& Meyer Verlag.

4. Ferguson Ch., \& Turbyfill R. (2013). Discovering Orienteering: Skills, Techniques, and Activities. USA: Human Kinetics.

5. Gjerset, A., \& Mo, K. (1975). En undersoklese av norske elite o-loperes adferdsmonster ved tidsstudieteknik. Oslo: NIH.

6. Hogedal, L., \& Putkonen, P-O. (1975). Analys av svenska elit-löpares orienteringsteknik. Stockholm: GIH Stockholm.

7. Johansen, B.J. (1997). Thinking in Orienteering. Scientific journal of orienteering., 13, pp. 38-46.

8. McNeill, C. (2014).Orienteering: Skills-Technigues-Training. Ramsbury: Crowood Press.

9. Nilsson, J. (1980). Orientering. Stockholm: Trygg Hansa.

10. Novotný, R. (2007). Soustředit se, věřit si a jit si to svoje. Orientační běh - časopis orientačních sportü., 4, pp. 46

11. Seiler, R., (1987). Casual Attribution of Mistakes in Orienteering. Scientific Journal Of Orienteering, 3, pp. 3-21 